\title{
The effect of different cooking methods on folate retention in various foods that are amongst the major contributors to folate intake in the UK diet
}

\author{
Derek J. McKillop, Kristina Pentieva*, Donna Daly, Joseph M. McPartlin, Joan Hughes, J. J. Strain, \\ John M. Scott and Helene McNulty \\ Northern Ireland Centre for Food and Health (NICHE), University of Ulster, Coleraine BT52 1SA, Northern Ireland, UK
}

(Received 14 January 2002 - Revised 04 July 2002 - Accepted 15 August 2002)

\begin{abstract}
Folate intake is strongly influenced by various methods of cooking that can degrade the natural forms of the vitamin in foods. The aim of the present study was to determine the effect of different cooking methods on folate retention in various foods that contribute to folate intake in the UK diet. Typical purchasing and cooking practices of representative food folate sources were determined from a questionnaire survey of local shoppers ( $n$ 100). Total folate was determined by microbiological assay (Lactobacillus casei NCIMB 10463) following thermal extraction and tri-enzyme ( $\alpha$-amylase, protease and conjugase) treatment in raw foods and after typical methods of cooking. Boiling for typical time periods resulted in only $49 \%$ retention of folate in spinach $(191.8$ and $94.4 \mu \mathrm{g} / 100 \mathrm{~g}$ for raw and boiled spinach respectively; $P<0.005)$, and only $44 \%$ in broccoli $(177.1$ and $77.0 \mu \mathrm{g} / 100 \mathrm{~g}$ for raw and boiled broccoli respectively, $P<0.0001)$. Steaming of spinach or broccoli, in contrast, resulted in no significant decrease in folate content, even for the maximum steaming periods of $4.5 \mathrm{~min}$ (spinach) and $15.0 \mathrm{~min}$ (broccoli). Prolonged grilling of beef for the maximum period of $16.0 \mathrm{~min}$ did not result in a significant decrease in folate content $(54.3$ and $51.5 \mu \mathrm{g} / 100 \mathrm{~g}$ for raw and grilled beef respectively). Compared with raw values, boiling of whole potatoes (skin and flesh) for $60.0 \mathrm{~min}$ did not result in a significant change in folate content $(125.1$ and $102.8 \mu \mathrm{g} / 100 \mathrm{~g}$ for raw and boiled potato respectively), nor was there any effect on folate retention whether or not skin was retained during boiling. These current results show that the retention of folate in various foods is highly dependent both on the food in question and the method of cooking. Thus, public health efforts to increase folate intake in order to improve folate status should incorporate practical advice on cooking.
\end{abstract}

Food folate retention: Cooking methods: Food folates: Dietary folate intake

Optimal folate status may have a role in the prevention of cardiovascular disease via plasma homocysteine-lowering (Boushey et al. 1995), and possibly in the prevention of certain cancers (Branda \& Blickenderfer, 1993; Kim et al. 1997; Jacob et al. 1998; Choi \& Mason, 2000). However, the most compelling evidence for the benefit of optimal folate status is its link with the prevention of neural tube defects (Medical Research Council Vitamin Study Research Group, 1991; Czeizel \& Dudas, 1992; Botto et al. 1999). The national committees tasked with public health in the UK, USA and Australia (Department of Health, 1992; Public Health Service Centers for Disease Control and Prevention, 1992; National Health and Medical Research Council, 1993) have recommended an extra
$400 \mu \mathrm{g}$ folic acid/d in addition to normal dietary folate intake to prevent the occurrence of neural tube defects. However, more recent studies suggest that an additional intake of $200 \mu \mathrm{g}$ folic acid/d may be optimal both for the prevention of neural tube defect occurrence (Daly et al. 1997) and for the lowering of plasma homocysteine (Ward et al. 1997). This level could potentially be achieved by doubling the current dietary folate intake of about $190 \mu \mathrm{g} / \mathrm{d}$ in the UK (Ball, 1998) through the increased consumption of folate-rich foods.

Natural folates are a group of water-soluble compounds with similar biological activity to the synthetic vitamin, folic acid. Unlike folic acid, which is a fully oxidised molecule, natural folates are reduced at the 5, 6, 7 and 8 
positions of the pteridine ring and so are prone to oxidative cleavage at the $\mathrm{C}_{9}-\mathrm{N}_{10}$ bond producing two degradation products, a pteridine and $p$-aminobenzoylglutamate (Murphy et al. 1976, 1978). Both of these molecules are inactive in themselves and cannot be biologically converted to any active folate form (Scott, 2001). In addition, natural folates are predominately polyglutamates, containing up to seven L-glutamate residues attached to the $p$-aminobenzoic group by $\gamma$-peptide linkage. The degree of glutamation does not appear to impact on folate stability (Gregory, 1996). However, the introduction of a group onto the $\mathrm{N}_{5}$ has a stabilising effect on the oxidative cleavage process (Eitenmiller \& Landen, 1999).

Compared with other water-soluble vitamins, in particular ascorbic acid, literature on the extent and mechanisms of folate loss during processing is limited (Ball, 1998). Folate losses during cooking and preparation are the result of a combination of thermal degradation and leaching of the vitamin into the cooking water (Eitenmiller \& Landen, 1999). The degree of loss can be influenced by environmental factors, including $\mathrm{pH}, \mathrm{O}_{2}$ content, metal ion concentrations, antioxidant levels, duration and product:water ratio (Keagy, 1985; Gregory, 1989; Hawkes \& Villota, 1989). Extensive losses of folate have been reported in boiled vegetables (Hurdle et al. 1968; Lin et al. 1975; Leichter et al. 1978; Dang et al. 2000) and baked meats (Vahteristo et al. 1998). However, studies specifically designed to investigate the impact of different cooking methods on folate content are limited. Furthermore, most studies comparing folate losses between methods are based on industrial, rather than domestic processes. The aim of the present study was to determine the effect of different cooking methods on folate retention in various foods that are amongst the major contributors to folate intake in the UK diet.

\section{Materials and methods}

The foods selected and the methods of cooking chosen in the present study were determined on the basis of an initial examination of purchasing and cooking practices of a sample of the general public. Thus, the overall study design comprised two separate components. Part 1 consisted of a consumer questionnaire focusing on food folate sources; part 2 was the determination of folate retention in foods following cooking, under conditions considered to be 'typical' on the basis of the survey in part 1 .

\section{Consumer questionnaire}

A questionnaire survey of local shoppers (n 100) was conducted with the objective of establishing typical purchasing and cooking practices of consumers of foods representing major dietary sources of folate. The questionnaire comprised a series of open questions to ascertain the form of purchase (e.g. fresh or frozen) and typical cooking practices of four foods representing the major contributors to folate intake in the UK diet (Ministry of Agriculture, Fisheries and Food, 1994). Cereal products, the largest folate contributors (accounting for $21 \%$ of total folate intake), were not included in this present study since they do not normally require post-purchase cooking. The study focused on vegetables, the next most important category, accounting for $16 \%$ of total folate intake, with leafy green vegetables being the largest sub-category (Ministry of Agriculture, Fisheries and Food, 1994), of which spinach and broccoli were selected for investigation as representative items. Potato (which is classified independently of vegetables) is reported to be the next most important source (Ministry of Agriculture, Fisheries and Food, 1994), providing $14 \%$ of total folate and was, therefore, selected for investigation. Finally, beef was selected, as it represents one of the major sources of meat folates, which account for $9 \%$ of total folate intake (Ministry of Agriculture, Fisheries and Food, 1994). The questionnaire did not attempt to determine typical cooking times as it was felt that consumers do not normally measure this and would therefore not be able to recall it with any degree of accuracy.

A large local retail outlet, Tesco, was the location selected for administration of the questionnaire. The questionnaire was administered over three different days (two weekdays plus a Saturday) and at three different times of the day (morning, afternoon or evening) in order to obtain an average sample of 100 shoppers.

\section{Food samples}

Purchase of food samples. Cooking stability experiments were performed on three separate occasions; on each occasion foods were sourced from different local retail outlets (Tesco, Safeway and Sainsbury). Samples of broccoli, spinach, potato and beef (steak) were purchased on the evening prior to analysis. Spinach, broccoli and beef were stored overnight at $2-8^{\circ} \mathrm{C}$, and potatoes were stored at room temperature.

Preparation of food samples. On each day of preparation of food samples, three packets of spinach $(300 \mathrm{~g}$ each) and three heads of broccoli were removed from supermarket packaging and condensation removed by blotting dry on paper towels. Fourteen $(25 \mathrm{~g})$ homogenous samples were prepared for both spinach (leaves were taken in random order from each packet of spinach) and broccoli (florets were cut from each part of the broccoli head). Two samples were retained for duplicate determination of folate content in the raw food and the remaining twelve were divided for duplicate examination of two cooking methods at three time points. Twelve average sized potatoes were washed and blotted dry and allocated to duplicate analysis of four treatments (raw with skin retained, peeled then boiled for $60.0 \mathrm{~min}$, boiled for $60.0 \mathrm{~min}$ in skin, boiled for $60.0 \mathrm{~min}$ then peeled). Three potatoes were used for each treatment. For the samples of raw potato with skin retained, small pieces of each potato were cut to prepare the two individual samples of $25 \mathrm{~g}$. In the case of the cooked potato samples, the whole potatoes were mashed after cooking and from the mashed material, individual samples of $25 \mathrm{~g}$ were prepared. Potatoes requiring peeling prior to cooking were peeled with a traditional potato peeler, whereas those peeled after cooking were peeled with a butter knife. Four lean beef steaks were blotted dry on paper towels, any visible fat was carefully removed and the remaining meat was cut into eight 
$25 \mathrm{~g}$ portions. Two were retained for duplicate determination of folate content in the raw food and the remaining six were allocated to duplicate examination of the effect of grilling at three time points.

Cooking of food samples. Preliminary experiments were conducted to determine the cooking time (min) required to achieve consistencies corresponding to 'undercooked', 'cooked' and 'overcooked' for the various food samples and cooking methods. In the case of spinach, broccoli and beef, all three time points (i.e. corresponding to 'undercooked', 'cooked' and 'overcooked') were considered, whereas for potato samples, only one time period ('cooked', i.e. intact but tender enough to mash) was examined. Instead, different methods of preparation of potatoes for boiling were examined.

Samples for spinach and broccoli were placed in covered stainless-steel saucepans containing $100 \mathrm{ml}$ boiling water (unsalted). In order to ensure that the cooked samples would correspond to the raw ones, each sample was cooked in an individual saucepan and the pieces collected through a fine sieve. The effect of duration of boiling was investigated in duplicate at $0.0,1.5,3.5$ or $5.0 \mathrm{~min}$ for spinach, and at $0 \cdot 0,5 \cdot 0,10 \cdot 0$ or $15 \cdot 0 \mathrm{~min}$ for broccoli. Duplicate potato samples for each treatment (raw with skin retained, peeled then boiled for $60.0 \mathrm{~min}$, boiled for $60.0 \mathrm{~min}$ in skin, boiled for $60.0 \mathrm{~min}$ then peeled) were placed in covered stainless-steel saucepans containing $250 \mathrm{ml}$ boiling water (unsalted) and simmered for $60.0 \mathrm{~min}$.

Steaming of spinach and broccoli was conducted in a domestic split-level steamer. Unsalted water was taken to boiling temperature prior to the addition of the food samples. The effect of duration of steaming was investigated in duplicate at $0.0,1.5,3.0$ or $4.5 \mathrm{~min}$ and at 0.0 , $5 \cdot 0,10 \cdot 0$ or $15 \cdot 0 \mathrm{~min}$ for spinach and broccoli respectively. Beef samples were placed on the middle shelf of a preheated domestic electric-cooker grill. The effect of duration of cooking on folate content was investigated at $0 \cdot 0,6 \cdot 0,11 \cdot 0$, and $16 \cdot 0 \mathrm{~min}$. Sample weight was based on a raw sample that took account of the weight changes as a result of cooking.

Sampling. Cooking (all samples) was terminated by placing samples in an ice-water bath. In order to avoid differences in the moisture contents of food samples cooked by different methods of cooking for different time periods, samples of spinach, broccoli and steak were weighed raw before cooking. Food samples (corresponding to $25 \mathrm{~g}$ raw weight) were strained and blotted dry after cooking. Potato samples for each preparation group were blotted dry prior to mashing and removal of a $25 \mathrm{~g}$ sample (cooked weight). All cooked samples of spinach, broccoli, beef and potato were homogenised in $100 \mathrm{ml}$ $N$-(2-hydroxyethyl)piperazine- $N^{\prime}$-(2-ethanesulfonic acid) (Hepes)/2-( $N$-cyclohexylamino)ethanesulfonic acid (Ches) buffer (50 mM-Hepes, $50 \mathrm{~mm}$-Ches, $20 \mathrm{~g}$ ascorbic acid/1 and $10 \mathrm{mM}$-2-mercaptoethanol, $\mathrm{pH} 7.85$ ) in a domestic food processor. The homogenates $(500 \mu \mathrm{l}$ aliquots $)$ were stored at $-80^{\circ} \mathrm{C}$ for subsequent analysis.

\section{Determination of folate content of food samples}

All preparative and analytical procedures were performed under subdued light and contact with air was minimised. Rat serum obtained from Sigma Chemical Co. (Poole, Dorset, UK) was dialysed for $24 \mathrm{~h}$ at $2-4^{\circ} \mathrm{C}$ in 1 litre Hepes/Ches buffer, pH 7.85 (50 mM-Hepes, 50 mM-Ches, $20 \mathrm{~g}$ ascorbic acid/1 and $10 \mathrm{mM}-2$-mercaptoethanol, $\mathrm{pH}$ 7.85) containing $2 \mathrm{~g}$ acid-washed $\mathrm{C}$ powder (Sigma Chemical Co.). The crude rat serum conjugase was filtered through a $0.2 \mu \mathrm{m}$ syringe filter (Sartorius AG, Göttingen, Germany) and divided into $1 \mathrm{ml}$ portions and stored at $-80^{\circ} \mathrm{C}$. Solutions of $\alpha$-amylase and protease (Sigma Chemical Co.) were prepared fresh each day by dissolution in ultrapure water at concentrations of 10 and $20 \mathrm{mg} / \mathrm{ml}$ respectively. Trace levels of folate were removed from the enzyme solutions by treatment with activated charcoal, as described by Tamura (1998). All enzyme solutions were tested for folate content and no measurable folate was detected.

Thawed samples $(500 \mu \mathrm{l})$ were mixed in $50 \mathrm{ml}$ Oak Ridge centrifuge tubes (Nalgen, Rochester, NY, USA) with $4.5 \mathrm{ml}$ Hepes/Ches buffer, $\mathrm{pH} 7.85$, which had been taken to $100^{\circ} \mathrm{C}$ by immersion in a boiling water-bath. Samples were maintained at $100^{\circ} \mathrm{C}$ for $10 \mathrm{~min}$. After rapid cooling on ice, $500 \mu \mathrm{l} \alpha$-amylase was added to each tube and incubated for $2 \mathrm{~h}$ at $37^{\circ} \mathrm{C}$. Prior to the addition of conjugase, the $\alpha$-amylase was thermally deactivated by immersion in a boiling water bath for $5 \mathrm{~min}$ followed by rapid cooling on ice. Rat serum conjugase $(100 \mu \mathrm{l})$ was added to each sample and incubated for $2 \mathrm{~h}$ at $37^{\circ} \mathrm{C}$. Conjugase was thermally deactivated $\left(100^{\circ} \mathrm{C}\right.$ for $5 \mathrm{~min}$ followed by rapid cooling on ice) prior to the addition of $500 \mu \mathrm{l}$ protease and incubation for $2 \mathrm{~h}$ at $37^{\circ} \mathrm{C}$. Protease was deactivated by immersion of sample tubes in a boiling water bath for $5 \mathrm{~min}$ followed by rapid cooling on ice and centrifugation at $3000 \mathrm{~g}$ for $15 \mathrm{~min}$. The resulting supernatant fraction was divided into portions in $3 \mathrm{ml}$ tubes, flushed with $\mathrm{N}_{2}$ and stored for up to 3 months at $-80^{\circ} \mathrm{C}$ until folate determination.

Total folate was determined by microbiological assay with Lactobacillus casei NCIB 10463 (Molloy \& Scott, 1997) following thermal extraction and tri-enzyme ( $\alpha$-amylase, protease and conjugase) treatment. The calibration of the assay was performed using folic acid (Sigma Chemical Co.). Under the conditions of the assay in our laboratory ( $\mathrm{pH} 6.7$ of the assay medium), L. casei showed equivalent responses to the main folate derivatives (folic acid, 5-methyl tetrahydrofolate, 5-formyl tetrahydrofolate, 10-formyl tetrahydrofolate and tetrahydrofolate). A similar response by $L$. casei was observed when the $\mathrm{pH}$ of the assay medium was adjusted to $6 \cdot 2$. For quality control purposes, spinach-extract samples were prepared by thermal extraction and tri-enzyme treatment. The interassay $\mathrm{CV}$ of the folate content of spinach extract quality control samples was $5.5 \%$ ( $n$ 48). Recovery studies were performed by spiking the spinach quality control samples with folic acid, $(6 S)$-5-methyl tetrahydrofolate and $(6 S)$ 5-formyl tetrahydrofolate, at three different levels: $0 \cdot 25$, 0.50 and $1.00 \mu \mathrm{g}$. The spiked samples underwent the entire procedure of food folate analysis (thermal extraction, tri-enzyme treatment and microbiological assay). The recovery for different folate derivatives was between 87 and $101 \%$. A linear response was demonstrated corresponding 
to the increased concentration of folate content of the spiked spinach samples. Samples for all treatment groups for each food were analysed together. All dilutions were carried out in an ascorbate solution (5g/l) using an automated dilutor (Hamilton, Bonaduz AG, Bonaduz, Switzerland).

\section{Statistical methods}

The consumer questionnaire was analysed by SPSS (version 9.0.1; SPSS UK Ltd, Chertsey, Surrey, UK). Statistical evaluation of folate values was analysed by Data Desk (version 6; Data Description Inc., Ithaca, NY, USA). Differences in folate content between time points and between cooking methods were established by ANOVA and paired $t$ test. Differences were considered significant at $P<0.05$.

\section{Results}

\section{Consumer questionnaire}

Of 190 people approached at random, 100 completed the questionnaire, of which $71 \%$ were female and $29 \%$ were male. The age profile ranged from 18 to $>85$ years with a median age range of 36-45 years. The proportion of the survey population that regularly consumed each of the four food items under examination is presented in Fig. 1. Spinach was the food item that was least popular amongst the sample surveyed. Most respondents purchased fresh vegetables $(84 \%$ ), with $25 \%$ reporting purchase of frozen vegetables. Steak was the most popular form of beef purchased ( $83 \%$ of the sample). Microwaving as a method of cooking (as opposed to a means of reheating) was not popular with our respondents, with only 3,9 and
$6 \%$ reporting a preference for this method of cooking of spinach, broccoli and potatoes respectively. The two most popular cooking methods employed for green vegetables were boiling (49\% of respondents) and steaming (45\% of respondents). Boiling was the preferred method of cooking potatoes, with $79 \%$ of the sample reporting a preference for this method. Grilling was the most popular method of cooking beef (steak), with $48 \%$ of respondents stating a preference for this method.

\section{The effect of different cooking methods on folate retention in various foods}

Results showing folate in foods following typical cooking procedures are presented in Table 1. Boiling resulted in a significant decrease in the folate content of spinach (51\%,P<0.005) and broccoli $(56 \%, P=0.0001)$ compared with the raw food. Compared with raw spinach or broccoli, no significant losses of folate were observed as a result of steaming. Overall, steaming compared with boiling (for typical cooking times) resulted in significantly greater retention of folate for both spinach (100 v. 49\%, $P<0.0001)$ and broccoli (91 v. $44 \%, P<0.0001)$. Boiling of whole potatoes (skin and flesh) for $60.0 \mathrm{~min}$ did not result in a significant reduction in folate content compared with the raw value. Grilling of beef for $11.0 \mathrm{~min}$ did not significantly change its folate content compared with the raw sample.

\section{Folate retention during prolonged duration of cooking}

The effects of duration of cooking on folate retention are presented in Fig. 2. Significant decreases in folate retention were observed with increasing duration of boiling of spinach and broccoli (Fig. 2). Steaming, in contrast, did not

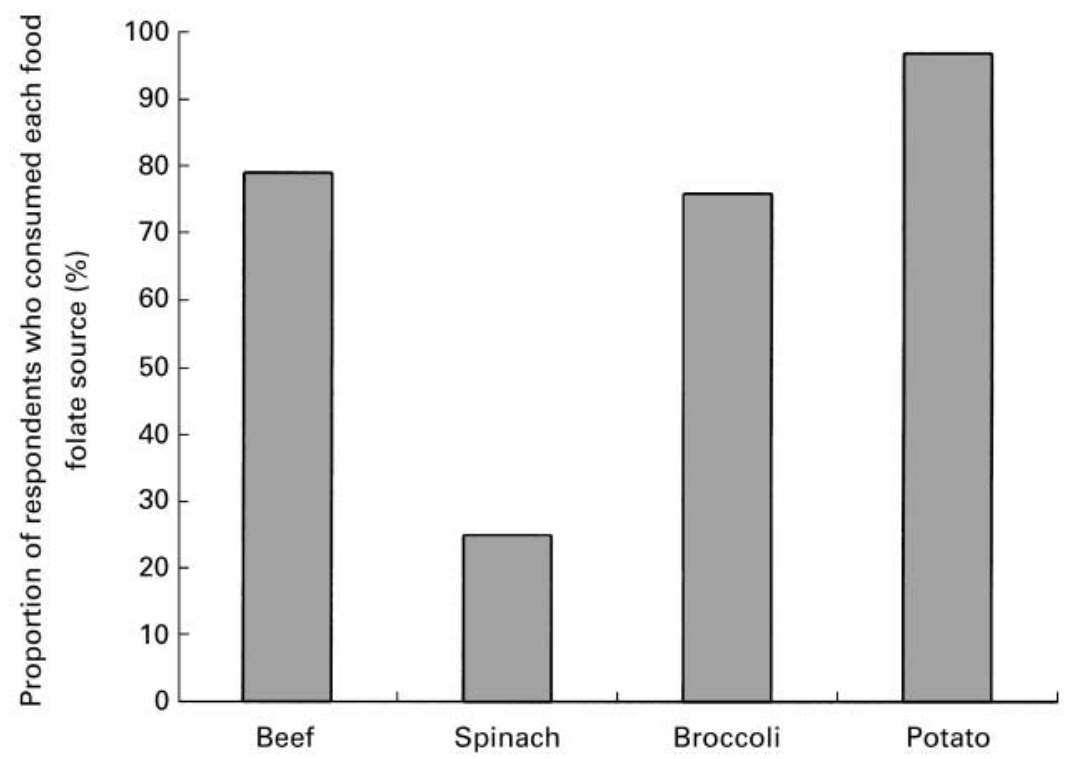

Fig. 1. Consumer questionnaire respondents (\%) who reported consuming four foods representing major food folate sources in the UK diet (Ministry of Agriculture, Fisheries and Food, 1994). The sample comprised shoppers (n 100) at a local retail outlet and the results were collected over three different days, at three different times of day. For details of questionnaire and procedures, see p. 682. 
Table 1. Folate retention in major food folate sources following typical cooking procedures $\dagger$ (Mean values with their standard errors for duplicate samples in three independent experiments)

\begin{tabular}{|c|c|c|c|c|c|c|}
\hline \multirow[b]{2}{*}{ Food } & \multirow[b]{2}{*}{ Cooking method } & \multirow[b]{2}{*}{ Cooking duration $(\min ) \ddagger$} & \multicolumn{2}{|l|}{ Raw food§ } & \multicolumn{2}{|c|}{ Cooked food§ } \\
\hline & & & Folate $(\mu \mathrm{g} / 100 \mathrm{~g})$ & SEM & Folate $(\mu \mathrm{g} / 100 \mathrm{~g})$ & SEM \\
\hline Spinach & Boiled & 3.5 & $191 \cdot 8$ & $5 \cdot 8$ & $94 \cdot 4^{\star \star \star}$ & $13 \cdot 3$ \\
\hline Spinach & Steamed & $3 \cdot 0$ & 189.5 & $9 \cdot 0$ & $218 \cdot 5$ & $22 \cdot 6$ \\
\hline Broccoli & Boiled & $10 \cdot 0$ & $177 \cdot 1$ & $8 \cdot 5$ & $77 \cdot 0^{\star \star \star \star}$ & 3.6 \\
\hline Broccoli & Steamed & $10 \cdot 0$ & $172 \cdot 0$ & $9 \cdot 4$ & $156 \cdot 2$ & 14.5 \\
\hline Potato & Boiled & $60 \cdot 0$ & $125 \cdot 1$ & $11 \cdot 7$ & $102 \cdot 8$ & $15 \cdot 0$ \\
\hline Beef & Grilled & $11 \cdot 0$ & 54.3 & $4 \cdot 8$ & 50.6 & $5 \cdot 8$ \\
\hline
\end{tabular}

Mean values were significantly different from those of the raw food (paired $t$ test: ${ }^{\star \star \star} P<0.005,{ }^{\star \star \star \star} P<0.0001$

†'Typical' cooking procedures were established from the results of a consumer questionnaire (for details see p. 682).

$\ddagger$ Times shown reflect the duration required to cook the food item (determined from preliminary experiments, i.e. not 'undercooked' or 'overcooked'; for details, see p. 683).

$\S$ To avoid differences in moisture content as a result of different cooking procedures, spinach, broccoli and beef were weighed raw before cooking and values therefore given per $100 \mathrm{~g}$ raw weight. Values for potatoes relate to whole potatoes (skin and flesh) and are given per $100 \mathrm{~g}$ raw or cooked weight as appropriate (for details of procedures see p. 682).
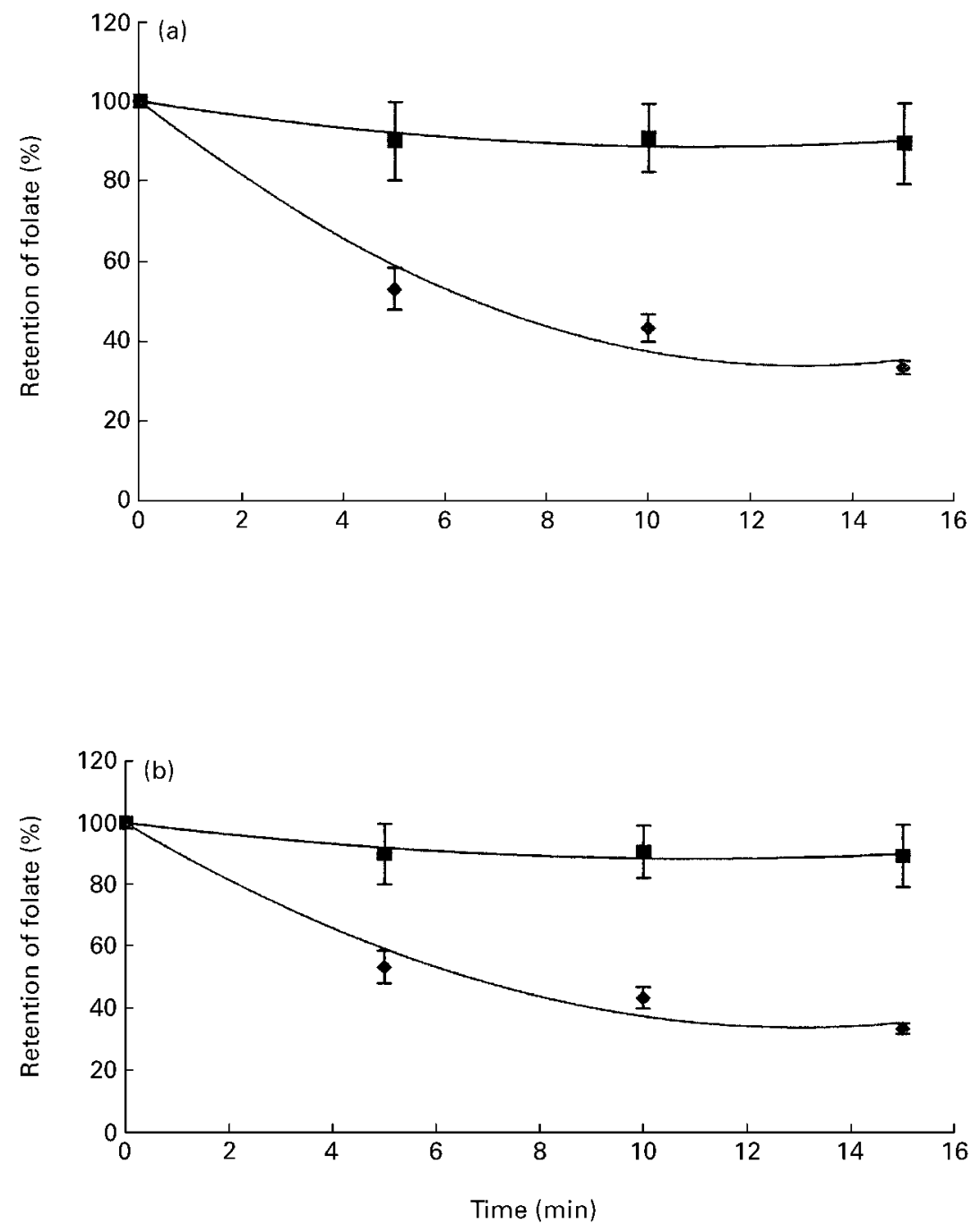

Fig. 2. The effect of duration and method of cooking on folate retention in: (a), spinach; (b), broccoli. $\bullet$, Boiled; $\mathbf{\square}$, steamed. For details of samples and procedures, see p. 682. Values are means for six samples, with their standard errors shown by vertical bars. 


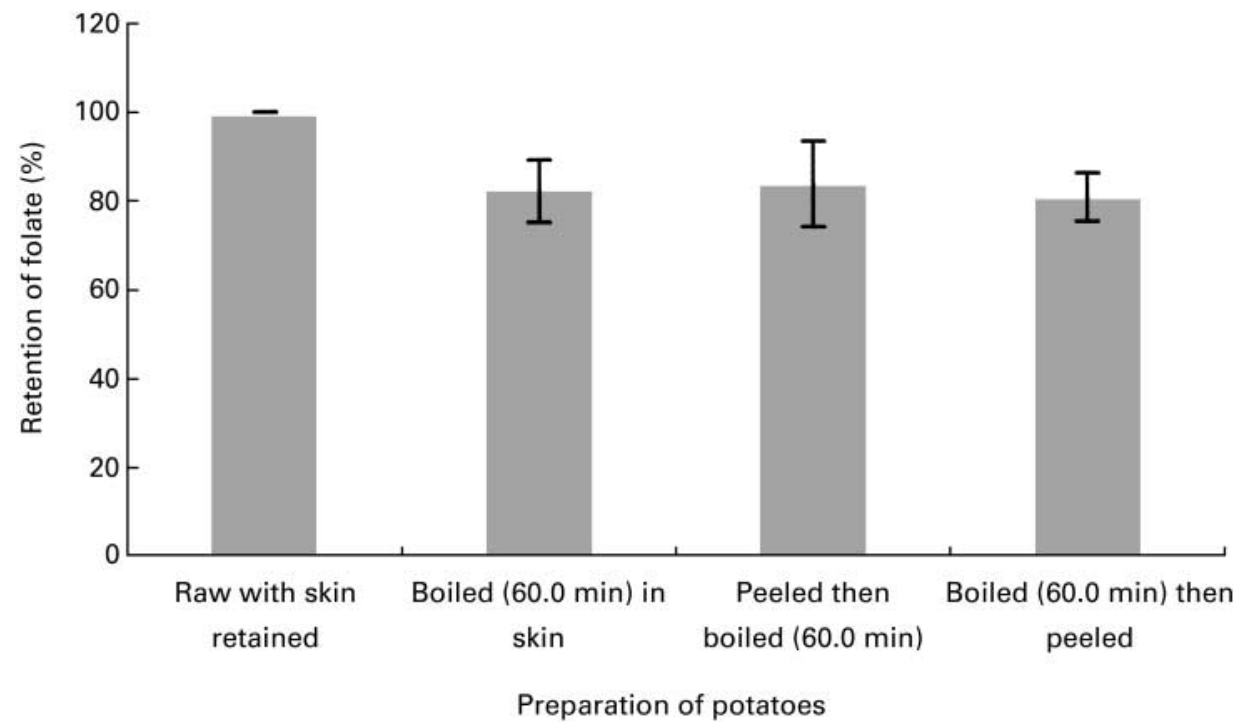

Fig. 3. Impact of preparation of potatoes on folate retention during boiling. For details of samples and procedures, see p. 682 . Values are means for six samples, with their standard errors shown by vertical bars. No significant differences were observed for folate content when various cooking procedures were compared (ANOVA).

result in a significant decrease in folate content, even after the maximum steaming periods of $4.5 \mathrm{~min}$ and $15.0 \mathrm{~min}$ for spinach and broccoli respectively. Grilling of beef for the maximum period of 16.0 min did not result in a significant loss in folate content $(54.3$ v. $51.5 \mu \mathrm{g} / 100 \mathrm{~g}, P=0.5)$.

\section{The effect of preparation of potatoes on folate retention during boiling}

The effects of different preparation techniques on folate retention in potatoes during boiling are presented in Fig. 3. The presence or absence of potato skin had no significant impact on folate retention during boiling.

\section{Discussion}

The present study investigated the influence of typical cooking methods on folate retention in foods that are amongst the major contributors to folate intake in the UK diet. The consumer questionnaire survey revealed a preference for fresh produce and traditional modes of cooking (boiling, steaming and grilling). Potatoes were consumed by three times as many respondents as spinach and were cooked predominantly by boiling (almost $80 \%$ of the respondents). Green vegetables (spinach and broccoli) were typically prepared by boiling (49\% of respondents) and steaming (45\% of respondents). Grilling was reported to be the most popular method of cooking beef, with almost half $(48 \%)$ of the respondents preferring this method.

Our present results showed significant reductions of 51 and $56 \%$ in the folate content of spinach and broccoli compared with raw values respectively, as a result of boiling for typical time periods. In contrast, steaming of spinach or broccoli did not result in a significant loss of folate content, even after the maximum steaming periods of $4.5 \mathrm{~min}$ and 15.0 min respectively, which produced overcooked consistencies. Our present results, showing markedly greater folate retention following steaming compared with boiling of green vegetables under domestic conditions, are in good agreement with the findings of De Souza \& Eitenmiller (1986) and Lund (1988), based on industrial processing. They reported that steam blanching resulted in greater retention of folate compared with water blanching. Likewise, other forms of cooking (not examined here) that minimise the direct contact of food with the cooking water such as pressure cooking (Dang et al. 2000) and microwave cooking (Chen et al. 1983; Klein, 1989) have been found to be preferable to boiling in terms of folate retention.

These results are in good agreement with Leichter et al. (1978), who reported a folate loss of $62 \%$ for broccoli boiled for $10.0 \mathrm{~min}$, compared with $56 \%$ for the same duration in the current study. Likewise, DeSouza \& Eitenmiller (1986) reported a $62 \%$ loss in the folate content of broccoli after water blanching (i.e. treated in boiling water for 3.0 min) and Hurdle et al. (1968) reported a $59 \%$ reduction in folate content as a result of boiling broccoli for an unspecified time. The strong relationship between folate loss and duration of boiling demonstrated here may in part explain the discrepancy between the Leichter et al. (1978) findings of $78 \%$ loss in the folate content of spinach after $10.0 \mathrm{~min}$ of boiling, compared with the $51 \%$ folate loss after $3.0 \mathrm{~min}$ of boiling shown in the current study. However, De Souza \& Eitenmiller (1986) reported an $83 \%$ loss in spinach folate after water blanching for only $3.0 \mathrm{~min}$, a result that may be explained by the large water:product ratio associated with industrial blanching procedures. The large surface area of spinach is likely to make it more susceptible to the influence of water:product ratio (Klein, 1989) on leaching of folate from it compared with that of other vegetables.

Compared with green vegetables, relatively few studies have examined the folate loss associated with the preparation and cooking of potatoes. Although not considered to be particularly rich in folate, their high level of 
consumption means that they are major contributors to folate in the UK diet, accounting for $14 \%$ of total folate intake (Ministry of Agriculture, Fisheries and Food, 1994). Our present results show that compared with raw values, boiling of whole potatoes (skin and flesh) for $60.0 \mathrm{~min}$ did not result in a significant reduction in folate content. Furthermore, our present results indicate that folate is not concentrated in the skin region, as the folate content of peeled potatoes did not differ significantly from whole potatoes. In addition, the skin did not appear to impede leaching, as there was no significant difference in folate retention of potatoes boiled whole (with skin) compared with potatoes peeled prior to boiling. In contrast, Augustin et al. (1987) found that retention of potato skins significantly retarded the loss of folate during boiling. The precise distribution of folate in potatoes is unclear; however, it is likely to be dependent on maturity (Arthey, 1975) and possibly on the variety of potato.

The difference in folate losses during boiling between foods in the current study is worth noting. No loss in folate was observed for potato despite being boiled for $60.0 \mathrm{~min}$, compared with $51 \%$ folate loss from spinach boiled for only $3.0 \mathrm{~min}$. In addition, the folate loss from broccoli is comparable with that from spinach, despite being boiled for three times longer. Our findings, therefore, support the theory of Malin (1977) that surface area and geometric shape significantly affect the folate loss resulting from leaching. Leichter et al. (1978) reported that folate loss as a result of boiling was principally as a result of leaching, and not as a result of degradation of the folate molecule. In the current study, water samples were collected during one of the experiments. All of the folate lost from the food during cooking (both steaming and boiling) was accounted for in the cooking water (results not shown), which supports the view that folate losses during cooking are not related to folate degradation, but to leaching.

Folates of animal origin are reported to be stable during boiling and frying (Ball, 1998). In the current study we showed that cooking of beef (steak) by direct heat (grilling) also results in negligible folate loss, even after a prolonged period of grilling for $16.0 \mathrm{~min}$. However, Aramouni \& Godber (1991) reported decreases in the folate contents of beef liver of 41 and $50 \%$ as a result of broiling (grilling) and frying respectively. A possible explanation for this inconsistency may be that it relates to differences in cofactor forms of folate found in beef liver compared with muscle (Vahteristo et al. 1998), some of which may be more labile than others. In addition, the reported folate content in beef muscle $(9.0 \mu \mathrm{g} / 100 \mathrm{~g})$ is considerably less than that in liver $(240.0 \mu \mathrm{g} / 100 \mathrm{~g})$; therefore, losses are likely to be more marked in the latter.

It is well established that reported food folate values are affected by the method of analysis employed. The trienzyme methodology ( $\alpha$-amylase, protease and conjugase) used in the present study has been reported by a number of investigators to result in substantial increases in measurable folate, compared with traditional methods involving treatment with conjugase alone prior to quantification (Tamura, 1998). In the current study, we found folate values $(\mu \mathrm{g} / 100 \mathrm{~g}$ raw food) to be between $1 \cdot 3$ - and $6 \cdot 0$-fold higher than the published values (Holland et al. 1991): spinach 191 v. 150 , broccoli 175 v. 90, potato 125 v. 35, beef $54 v .9$. The increase of measurable folate after trienzyme treatment cannot be attributed to any folate contribution by the enzymes, because all the enzyme solutions used were purified and analytically proven to be free of folate. Thus, the reasonable explanation for this finding is that the bound folates were liberated from the food matrix as a result of enzyme treatment. In support of this, the difference in folate content was found to be much greater in the case of potato and beef compared with green vegetables, which might be expected given that potatoes and beef are rich in starch and protein, the target molecules of tri-enzyme digestion, in comparison with green vegetables, which are not rich in these substrates. In addition, the degradation of ascorbic acid (added to protect folates during analysis) at neutral $\mathrm{pH}$ can be prevented by the addition of the antioxidant, 2-mercaptoethanol (Wilson \& Horne, 1984), or by naturally occurring thiols and antioxidants in the foods. Thus, the impact of the introduction of 2-mercaptoethanol in addition to ascorbate in the extraction buffers in the present study (not typically used in the traditional methods) may have had a greater impact on recovery of intact folate in foods that are not rich in antioxidants, such as beef and potatoes, compared with antioxidant-rich foods such as green vegetables. Whatever the explanation, such marked differences in folate values using newer methodology compared with published values have major implications for the calculation of dietary folate intake (and therefore folate recommendations) and require further investigation.

In conclusion, we show that the retention of folate in various foods is highly dependent both on the food in question and the method of cooking. Folates of animal origin (i.e. beef) were found to be stable to cooking even for prolonged periods. Likewise, folate was well retained in potatoes during boiling and we found no evidence (from a folate perspective) to support the popular view that: 'the goodness is in the skin'. However, the method and duration of cooking of green vegetables were found to have marked effects on folate retention from this major food folate source. Public health efforts to increase folate intakes should, therefore, incorporate practical advice on cooking. For example, steaming in preference to boiling could be promoted as a means of doubling the folate content of cooked green vegetables. In addition, consumers choosing to boil green vegetables should be strongly discouraged from doing so for prolonged periods and should be advised to minimise the cooking water and utilise it for soups or gravy. These practical measures could make a substantial impact on folate intake from natural food sources and play a potential role in the prevention of folate-related diseases by helping to optimise folate status.

\section{Acknowledgement}

This project was supported by a grant from the Food Standards Agency, UK. 


\section{References}

Aramouni FM \& Godber JS (1991) Folate losses in beef liver due to cooking and frozen storage. Journal of Food Quality 14, $357-365$.

Arthey VD (1975) Quality of Horticultural Products. London: Butterworths.

Augustin J, Johnson SR, Teitzel C, True RH, Hogan JM, Toma RB, Shaw RL \& Deutsch RM (1987) Changes in the nutrient composition of potatoes during home preparation II. American Potato Journal 55, 653-662.

Ball GFM (1998) Folate. In Bioavailability and Analysis of Vitamins in Foods, pp. 439-496. London: Chapman and Hall.

Botto LD, Moore CA, Knotty MJ \& Erickson JD (1999) Medical progress: neural tube defects. New England Journal of Medicine 20, 1509-1519.

Boushey CJ, Beresford SA, Omenn GS \& Motulsky AG (1995) A quantitative assessment of plasma homocysteine as a risk factor for vascular disease: Probable benefits of increasing folic acid intakes. Journal of the American Medical Association 274, 1049-1057.

Branda RF \& Blickenderfer DB (1993) Folate deficiency increases genetic damage caused by alkylating agents in $\gamma$ irradiation in Chinese hamster ovary cells. Cancer Research 53, 5401-5408.

Chen TS, Song YO \& Kirsch AJ (1983) Effects of blanching, freezing and storage on folacin contents of spinach. Nutrition Reports International 28, 317-321.

Choi SW \& Mason JB (2000) Folate and carcinogenesis: An integrated scheme. Journal of Nutrition 130, 129-132.

Czeizel AE \& Dudas I (1992) Prevention of first occurrence of neural tube defects by periconceptional vitamin supplementation. New England Journal of Medicine 327, 1832-1835.

Daly S, Molloy A, Mills JL, Conley MR, Young LJ, Kirke PN, Weir DG \& Scott JM (1997) Minimum effective dose of folic acid for food fortification to prevent neural tube defects. Lancet 350, 1666-1669.

Dang J, Arcot J \& Shrestha A (2000) Folate retention in selected processed legumes. Food Chemistry 68, 295-298.

Department of Health (1992) Folic Acid and the Prevention of Neural Tube Defects. London: H. M. Stationery Office.

DeSouza SC \& Eitenmiller RR (1986) Effects of processing and storage on the folate content of spinach and broccoli. Journal of Food Science 51, 626-628.

Eitenmiller RR \& Landen WO (1999) Folate. In Vitamin Analysis for the Health and Food Science, pp. 411-465 [RR Eitenmiller and WO Landen, editors]. Boca Raton, FL: CRC Press.

Gregory JF (1989) Chemical and nutritional aspects of folate research: analytical procedures, methods of folate synthesis, stability and bioavailability of dietary folates. In Advances in Food and Nutrition Research, pp. 1-101 [JE Kinsella, editor]. New York: Academic Press.

Gregory JF (1996) Vitamins. In Food Chemistry, 3rd ed., pp. 531-608 [OR Fennema, editor]. New York: Marcel Dekker Inc.

Hawkes JG \& Villota R (1989) Folates in foods: reactivity, stability during processing and nutritional implications. Critical Reviews in Food Science and Nutrition 28, 439-538.

Holland B, Welch AA, Unwin ID, Buss DH, Paul AA \& Southgate DAT (1991) McCance and Widdowson's The Composition of Foods, 5th ed. Cambridge: Royal Society of Chemistry and Ministry of Agriculture, Fisheries and Food.

Hurdle ADF, Barton D \& Searles IH (1968) A method for measuring folate in foods and its application to a hospital diet. American Journal of Clinical Nutrition 21, 1202-1207.

Jacob RA, Gretz DM, Taylor PC, James SJ, Pogribny IP, Miller BJ, Henning SM \& Swendseid ME (1998) Moderate folate depletion increases plasma homocysteine and decreases lymphocyte DNA methylation in postmenopausal woman. Journal of Nutrition 128, 1204-1214.

Keagy PM (1985) Folacin: Microbiological and animal assays. In Methods of Vitamin Assay, 4th ed., pp. 445-471 [J Augustin, BP Klein and PB Venugopal, editors]. New York: John Wiley and Sons.

Kim YI, Pogribny IP, Basnakian AG, Miller JM, Selhub J, James SJ \& Mason JB (1997) Folate deficiency in rats induced DNA strand breaks and hypomethylation within the p53 tumour suppresser gene. American Journal of Clinical Nutrition 65, 46-52.

Klein BP (1989) Retention of nutrients in microwave-cooked foods. Boletin Asociacion Medica de Puerto Rico 81, 277-279.

Leichter J, Switzer VP \& Landymore AF (1978) Effect of cooking on folate content of vegetables. Nutrition Reports International 18, 475-479.

Lin KC, Luh BS \& Schweigert BS (1975) Folic acid content of canned garbanzo beans. Journal of Food Science 40, 562-565.

Lund D (1988) Effects of heat processing on nutrients. In Nutritional Evaluation of Food Processing, 3rd ed., pp. 319-354 [E Karmas and RS Harris, editors]. New York: Van Nostrand Reinhold.

Ministry of Agriculture, Fisheries and Food (1994) The Dietary and Nutritional Survey of British Adults: Further Analysis. London: H. M. Stationery Office.

Malin JD (1977) Total folate activity in Brussel sprouts: the effects of storage, processing, cooking and ascorbic content. Journal of Food Technology 12, 623-632.

Medical Research Council Vitamin Study Research Group (1991) Prevention of neural tube defects: results of the Medical Research Council Vitamin Study. Lancet 338, 131-137.

Molloy AM \& Scott JM (1997) Microbiological assay for serum, plasma and red cell folate using cryopreserved, microtiter plate method. Methods in Enzymology 281, 43-53.

Murphy M, Boyle PHM, Weir DG \& Scott JM (1978) The identification of the products of folate catabolism in the rat. British Journal of Haematology 38, 211-218.

Murphy M, Keating M, Boyle P, Weir DG \& Scott JM (1976) The elucidation of the mechanism of folate catabolism in the rat. Biochemistry and Biophysics Research Communications 71, $1017-1024$

National Health and Medical Research Council (1993) Revised Statement on the Relationship Between Dietary Folic Acid and Neural Tube Defects Such As Spina Bifida, 115th session. Australia: National Health and Medical Research Council.

Public Health Service Centers for Disease Control and Prevention (1992) Recommendations for the use of folic acid to reduce the number of cases of spina bifida and other neural tube defects. Morbidity and Mortality Weekly Report 41, 1-7.

Scott JM (2001) Methyltetrahydrofolate: the superior alternative to folic acid. In Nutraceuticals in Health and Disease Prevention, pp. 75-90 [K Krämer, PP Hoppe and L Packer, editors]. New York: Marcel Dekker Inc.

Tamura T (1998) Determination of food folate. Journal of Nutritional Biochemistry 9, 285-293.

Vahteristo LT, Lehikoinen KE, Ollilainen V, Koivistoinen PE \& Varo P (1998) Oven-baking and frozen storage affect folate vitamin retention. Food Science and Technology-LEB 31, 329-333.

Ward M, McNulty H, McPartlin JM, Strain JJ, Weir DG \& Scott JM (1997) Plasma homocysteine, a risk factor for cardiovascular disease, is lowered by physiological doses of folic acid. Quarterly Journal of Medicine 90, 519-524.

Wilson SD \& Horne DW (1984) High-performance liquid chromatographic determination of the distribution of naturally occurring folic acid derivatives in rat liver. Analytical Biochemistry 142, 429-535. 